\title{
Knowledge,Attitude and Practice of Shade Matching Among Dental Students - A Survey Based Analysis
}

\author{
B. John Rozar Raj ${ }^{1}$ and Manish Ranjan² \\ ${ }^{1}$ Saveetha Dental College and Hospitals, Saveetha Institute of Medical \\ and Technical Science, Saveetha University, Chennai 77, India \\ ${ }^{2}$ Reader, Department of Conservative Dentistry and Endodontics, Saveetha Dental College and Hospitals, \\ Saveetha Institute of Medical and Technical Science, Saveetha University, Chennai, India
}

\section{ABSTRACT}

This study was done to determine the knowledge, attitude and practise of shade matching techniques among dental students. Esthetics are of great importance in anterior teeth restorations. Shade selection plays an important role to achieve with a good aesthetic restoration that harmoniously blends to the natural dentition. Even though the colour may not be important to the physiological success of a dental restoration but it plays a dominant role in patient acceptance. Patients are currently demanding esthetic replacement that must match their existing dentition, and are more concerned about the shade match of their restoration rather than the quality of the restoration. This was a questionnaire based study. The study setting was a University setting. A pre-tested questionnaire with 10 questions was formulated for the collection of information. They were distributed to 100 dental students at a private dental institution and their answers were recorded. Excel Tabulation was done. SPSS was used to find out the association. In this study, all the dentists used only visual methods for shade matching. 62\% of them did not find any difficulty during the process of shade matching. The second opinion from another dentist for shade matching was preferred by $68 \%$ of them while only $6 \%$ of them asked for the patient's opinion during shade matching. Natural light was mostly used for shade matching. From the present study, we can conclude that the dental students had comparatively better understanding and knowledge about the principles of tooth shade selection. Majority of them did not face any difficulties during shade matching. They had better knowledge about the effectiveness and reliability of natural light during shade matching. But the knowledge about recent advances in shade matching was very less so better training and work experience can help them to understand about the advancements and the significance of shade matching.

KEY WORDS: AESTHETICS; COLOUR; KAP SURVEY; LIGHT; SHADE MATCHING.

\section{ARTICLE INFORMATION}

*Corresponding Author: manish@saveetha.com

Received 5th August 2020 Accepted after revision 24th Sep 2020

Print ISSN: 0974-6455 Online ISSN: 2321-4007 CODEN: BBRCBA

Thomson Reuters ISI Web of Science Clarivate Analytics USA and Crossref Indexed Journal

\section{Clarivate
Analytics}

NAAS Journal Score 2020 (4.31) SJIF: 2020 (7.728)

A Society of Science and Nature Publication,

Bhopal India 2020. All rights reserved.

Online Contents Available at: http//www.bbrc.in/

Doi: http://dx.doi.org/10.21786/bbrc/13.8/103 


\section{INTRODUCTION}

Nowadays, aesthetics has turned into an essential issue, as it appears to characterize one's character. Before, practical needs were the primary thought in dental treatment. Today, the concentration has moved towards dental aesthetics(Awinashe and Dugad, 2010). Reproducing the color of a natural tooth with artificial replacement still possesses a great challenge in modern dentistry(Vichi, Ferrari and Davidson, 2000; Azer et al., 2011). The success of restorative dentistry is principally determined based on functional and aesthetic results and is directly related to the accuracy of chair side selection(Hall, 1991; Joiner, 2004).

Esthetics are of great importance in anterior teeth restorations. Shade selection plays an important role to achieve with a good aesthetic restoration that harmoniously blends to the natural dentition. Even though the colour may not be important to the physiological success of a dental restoration but it plays a dominant role in patient acceptance. Patients are currently demanding esthetic replacement that must match their existing dentition, and are more concerned about the shade match of their restoration rather than the quality of the restoration(Hall, 1991).

So chair side selection has become a very important step in the overall treatment of the patient. Both visual and instrumental methods are used for shade selection with merits and demerits over each other. However, the visual method is still the most commonly used method due to relative simplicity and low cost(Hammad, 2003; Klemetti et al., 2006; Small, 2006).

One of the main concerns in the visual method is its highly subjective nature. Different individuals can have different shade perceptions for the same object(Hammad, 2003; Small, 2006). To achieve a good result, the four basic determinants are required. They are position,contour,texture and colour. The knowledge of the concept of colour is of great importance to achieve a good esthetics and its distribution of colour is very essential for dental shade matching(O’Brien et al., 1997). Colour combination will make the restoration look natural and attractive and also gives a good esthetic result. Color is a result of the interaction of three dimensions known as hue,chroma and value(Magne and Holz, 1996; Vanini, 1996).

Hue is denoted qualities that can be differentiated by colour words such as red,yellow,green,blue or purple. Chroma is a degree of saturation or the intensity of the hue such as light blue, dark blue and royal blue. Value describes the relative brightness of colours.(Terry, 2003). Visual colour matching is affected by many variables,such as age of the observer, his/her experience, possible colour deficiency, condition of the teeth observed and the light source(Gasparik et al., 2014; Clary et al., 2016).

Factors influencing the tooth colour may include congenital, metabolic, chemical, genetic, infectious and environmental. The shade and appearance of teeth is a heterogeneous phenomenon because many factors like opacity,translucency, light scattering, lighting conditions, gloss and the human eye and the brain influence the overall perception of the tooth colour(Joiner, 2004).

To ensure accuracy, various shade selection protocols have been devised and thorough knowledge of these protocols is important so that visual shade selections can be carried out with accuracy and precision(Okubo et al., 1998; Carsten, 2003; Dagg et al., 2004). Increasingly composite are placed in preference due to patients demands for esthetics as well as the clinical desire to do minimal preparation where possible and provide patients with bonded esthetic restoration(S et al., 2014; Sachan, Srivastava and Ranjan, 2016).

We have numerous highly cited publications on well designed clinical trials and lab studies (Govindaraju, Neelakantan and Gutmann, 2017; Azeem and Sureshbabu, 2018; Jenarthanan and Subbarao, 2018; Manohar and Sharma, 2018; Nandakumar and Nasim, 2018; Teja, Ramesh and Priya, 2018; Janani and Sandhya, 2019; Khandelwal and Palanivelu, 2019; Malli Sureshbabu et al., 2019; Poorni, Srinivasan and Nivedhitha, 2019; Rajakeerthi and Ms, 2019; Rajendran et al., 2019; Ramarao and Sathyanarayanan, 2019; Siddique and Nivedhitha, 2019; Siddique et al., 2019; Siddique, Nivedhitha and Jacob, 2019). This has provided the right platforms for us to pursue the current study.

The aim and objective of this study was to provide information on the level of awareness among the dental students in Chennai and the current status of knowledge, attitude and practice towards shade matching.

\section{MATERIAL AND METHODS}

The study was conducted in a private dental institution in Chennai. The study setting was carried out in a University setting with approval of the Institutional review board.

Inclusion criteria and Exclusion criteria: Undergraduate third year students, final year students and Interns were included in the study. Post graduate students and dental practitioners were excluded from the study.

Data Collection: A pre-tested questionnaire with 10 questions was formulated for the collection of information. The questionnaire was simple and brief. The self made questions were developed. The questionnaire included self made questions to assess about the knowledge, practise and awareness among the dental students regarding shade matching techniques and its recent advancements. The questionnaire was shared with 100 dental students and their answers were recorded using an online surveying tool( Google Forms).

Statistical Analysis: Data was entered in Microsoft Excel sheets. The data was imported and transferred to the computer and subjected to statistical analysis using SPSS(IBM SPSS Statistics, Version 24.0, Armonk, 
NY: IBM Corp]. Chi-square test was performed to find the association between the variables.The level for a statistical significance was set at $p<0.05$. The results were demonstrated in the form of bar graphs.

\section{Questionnaire}

1. Which method do you use for shade matching

?

a. Visual method

b. Digital method

2. Do you face any Difficulties during shade matching ?
a. Yes

b. No

3. When do you prefer doing the shade selection

a. Before starting the procedure

b. In between the procedure

4. Do you always ask for a second opinion during shade matching?

a. Yes

b. No

5. Do you ask for a patient's opinion during shade matching ?

a. Yes

b. No

6. What type of light do you use during shade matching?

a. Natural light

b. Dental unit light

7. Are you aware of the shade guides?

a. Yes

b. No

8. What is the most common shade used in your clinical practice?

$\begin{array}{ll}\text { a. } & \text { A1 } \\ \text { b. } & \text { A2 } \\ \text { c. } & \text { B1 } \\ \text { d. } & \text { B2 }\end{array}$

9. Do you do the shade selection separately for different regions of the tooth surface?

a. Yes

b. $\quad$ No

10. Are you aware of the recent advancements in shade matching ?

a. $\quad$ Yes

b. $\quad$ No

\section{RESULTS AND DISCUSSION}

The present study has provided information on knowledge about the principles of tooth shade selection in students with one year, two years and three years of experience. It has identified the areas where clinical training of the students need to be enhanced in relation to tooth shade selection. Figure 1 showed that all the participants of our study used only visual method for shade matching. In the study by Alruwaili.et.al, 56.8\% of the participants used visual (manual) method for tooth shade selection while the remaining participants used mechanical method or the combination of both the
methods(Alruwaili et al., 2018). Studies by Sambandam. et.al and Dagg.et.al also reported that the visual method was used more commonly for tooth shade selection than the instrumental method(Dagg et al., 2004; Sambandam and Ramesh, 2017). The high level of difficulty faced can be due to the fact that shade selection is done visually and the visual method has several known disadvantages and inaccuracies(Hall, 1991; Judeh and Al-Wahadni, 2009). The deficiencies can be controlled by utilizing the instrumental method which provides scientifically accurate shade reading. High tech gadgets like colorimeter and spectrophotometer are expensive and very difficult to operate in clinical setup. This is the reason for the visual method to remain as the most commonly used method for tooth shade selection worldwide(Okubo et al., 1998; Brewer, Wee and Seghi, 2004; Klemetti et al., 2006; Small, 2006).

Figure 1: Bar chart depicts the percentage distribution of the method used during shade matching. $\mathrm{X}$-axis denotes the years of experience. Y-axis denotes the number of students. All the dental students used only visual methods (Blue) for shade matching.

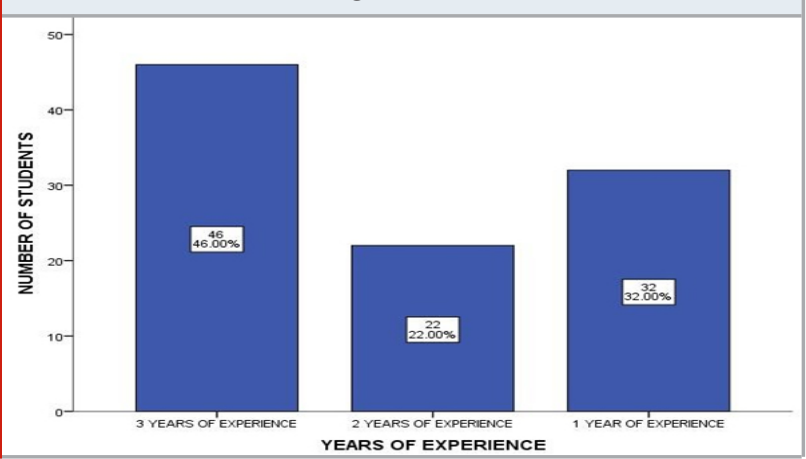

Figure 2: Bar chart depicts the association between difficulties faced during shade matching with respect to various years of experience. $\mathrm{X}$-axis denotes the years of experience. Y-axis denotes the number of students. Chisquare test was done and was found to be statistically significant (Pearson chi square, p value- $0.001 ;(<0.05)$. Students with three years of experience and two years of experience did not have any difficulties during shade matching while students with one year of experience did face difficulties.

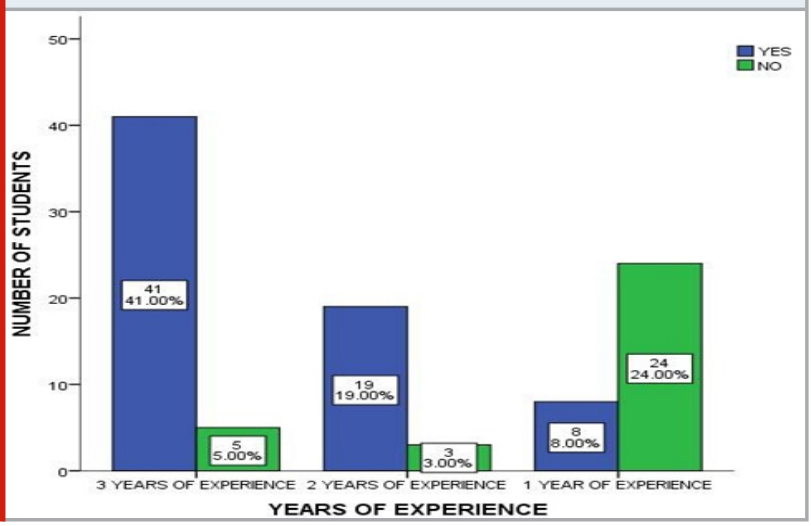


In our study, Figure 2 showed that the majority of the students with one year of experience did face many difficulties during their shade matching process while students with two years and three years of experience did not face any difficulties. In the study by Habib.et.al, majority of the respondents faced difficulty "sometimes" or " always" during the shade selection process(Habib, 2012). Even in the study by Klemetti.et.al, the majority of the participants faced difficulty during shade matching(Klemetti et al., 2006). Tooth shade selection can be regarded as a challenging procedure even for the experienced clinicians.

In our study, Figure 3 showed that more than half (57\%) of the participants preferred shade matching before starting the procedure while the remaining participants preferred to do it in between the procedure. In the study by Habib.et.al, $55.4 \%$ of the participants selected the shade at the end of the procedure(Habib, 2012). In the study by Iqbal.et.al, the observers preferred to select the shade matching in the end of the procedure after all the caries removal or after wetting the tooth surface(Iqbal, Shahid and Mm, 2017). Teeth tend to dry out towards the end of a dental procedure or when a rubber dam is applied. Therefore, it has been recommended to select shades before the procedure(Passon and Lambert, 1994; Joiner, 2004).

Figure 3: Bar chart depicts the association between knowledge about the time of shade matching with respect to various years of experience. $\mathrm{X}$-axis denotes the years of experience. Y-axis denotes the number of students. Chi-square test was done and was found to be statistically significant (Pearson chi square, p value- 0.003; $(<0.05)$. Students with three years and two years of experience preferred to do shade matching before starting the procedure while students with one year of experience preferred to do it in between the procedure.

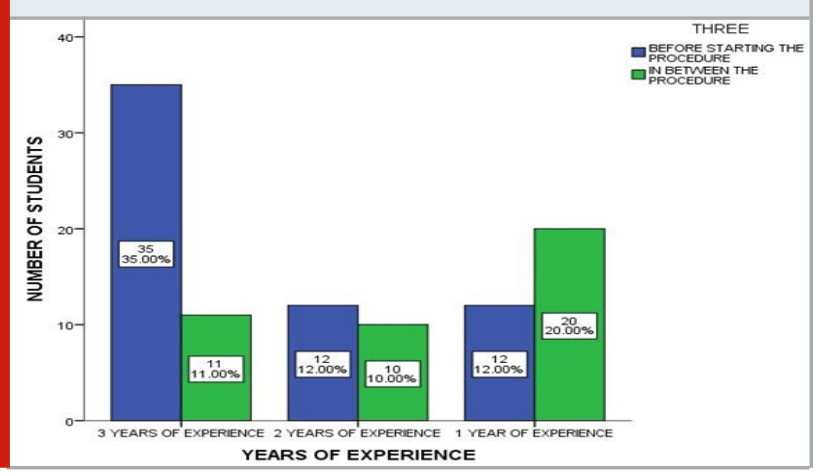

In our study, Figure 4 showed that the students with one year of experience $(28 \%)$ preferred to ask for a second opinion from other dentists than the students with three years of experience $(25 \%)$ during shade matching. In the study by Habib.et.al, second opinions during the shade selection process were sought either always or sometimes by most of the respondents(Habib, 2012).
Figure 4: Bar chart depicts the association between the attitude of asking for another dentist's opinion during shade matching with respect to various years of experience. $\mathrm{X}$-axis denotes the years of experience. $\mathrm{Y}$-axis denotes the number of students. Chi-square test was done and was found to be statistically significant (Pearson chi square, p value- $0.009 ;(<0.05)$. Students with one year of experience preferred to ask for a second opinion during shade matching more than the students with three years of experience.

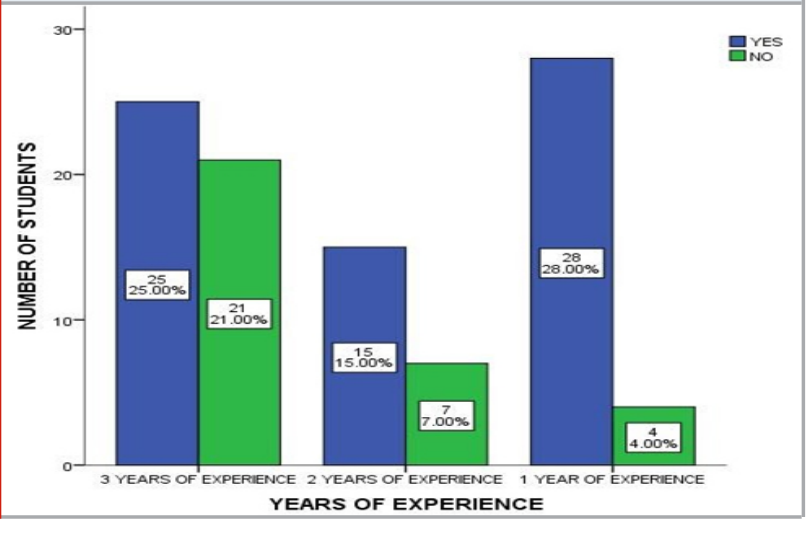

Figure 5: Bar chart depicts the association between the attitude of asking for the patient's opinion during shade matching with respect to various years of experience. $\mathrm{X}$-axis denotes the years of experience. Y-axis denotes the number of students. Chi-square test was done and was found to be statistically significant (Pearson chi square, $p$ value- $0.020 ;(<0.05)$. Majority of the students with three years of experience preferred to ask for the patient's opinion during shade matching.

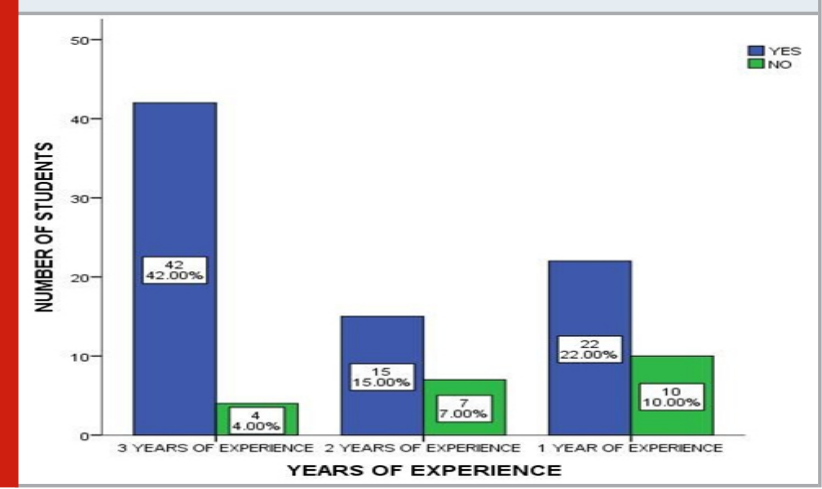

In our study, Figure 5 showed that $79 \%$ of the respondents always asked for the patient's opinion during shade matching. In the study by Sambandam.et.al, $80.7 \%$ of the respondents asked for the patient's opinion(Sambandam and Ramesh, 2017). In the study by Habib.et.al, patient's opinions were sought either always or sometimes by $90 \%$ of the respondents(Habib, 2012). Wagenaar.et.al stated that whenever an object such as a tooth is viewed for longer than 10 seconds, the colour vision capability of the eyes decreases rapidly and the perceived colour 
does not remain stable(Barrett et al., 2002; Wagenaar and Smit, 2004; Wee, 2006). In order to overcome this, get a second opinion from another dentist or from the patients themselves for a better outcome.

In our study, Figure 6 showed that the natural light (74\%) was the most commonly used light during shade matching. Students with two years and three years of experience found the natural light to be more reliable and effective than the dental unit light. But many students with one year of experience used dental light for shade matching. In the study by Alruwaili.et.al, dental unit light was used more than the natural light to do shade selection(Alruwaili et al., 2018). Studies by Sambandam. et.al and Habib.et.al showed similar results to our study. Natural light was used more than the other sources of light(Habib, 2012; Sambandam and Ramesh, 2017). Northern daylight is considered a standard for judging good lighting. However, in everyday dental practice we can't rely on sunlight so color-corrected fluorescent lights with CRI of 90 or above are recommended(Barna et al., 1981). The use of incandescent bulbs and dental unit lights is not recommended because of greater amount of light emittance(Wee, 2006).

Figure 6: Bar chart depicts the association between the knowledge about the type of light used during shade matching with respect to various years of experience. $\mathrm{X}$-axis denotes the years of experience. $\mathrm{Y}$-axis denotes the number of students. Chi-square test was done and was found to be statistically significant (Pearson chi square, $p$ value- $0.001 ;(<0.05)$. Students with three years and two years of experience used only natural light during shade matching. Students with one year of experience were less aware about the effectiveness and reliability of natural light and they mostly used dental unit light.

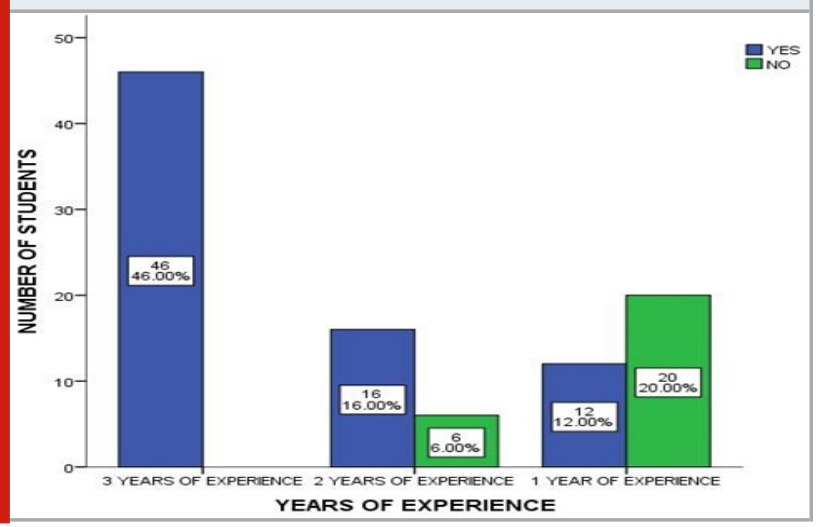

In our study, Figure 7 showed that more than half (69\%) the participants preferred to select the shade separately for different regions of the tooth surface. In the study by Sambandham.et.al, $66.7 \%$ of the participants preferred to determine the shades as cervical, middle and incisal thirds(Sambandam and Ramesh, 2017). Teeth are known to possess a gradation of colour from the cervical to the incisal area(Wee, 2006). According to Schwabacher. et.al and 0'Brien.et.al, the cervical color is modified by scattered light from the gingiva whereas the incisal colour is often translucent and is affected by its background. Therefore, shade should be selected separately for different regions of the tooth surface(Schwabacher, Goodkind and Lua, 1994; 0’Brien et al., 1997).

Figure 7: Bar chart depicts the association between awareness about shade matching separately for different regions of tooth surface with respect to various years of experience. $\mathrm{X}$-axis denotes the years of experience. $\mathrm{Y}$-axis denotes the number of students. Chi-square test was done and was found to be statistically significant (Pearson chi square, $p$ value- $0.001 ;(<0.05)$. Students with three years of experience were aware about the shade matching done separately for different regions of the tooth surface more than the students with one year of experience.

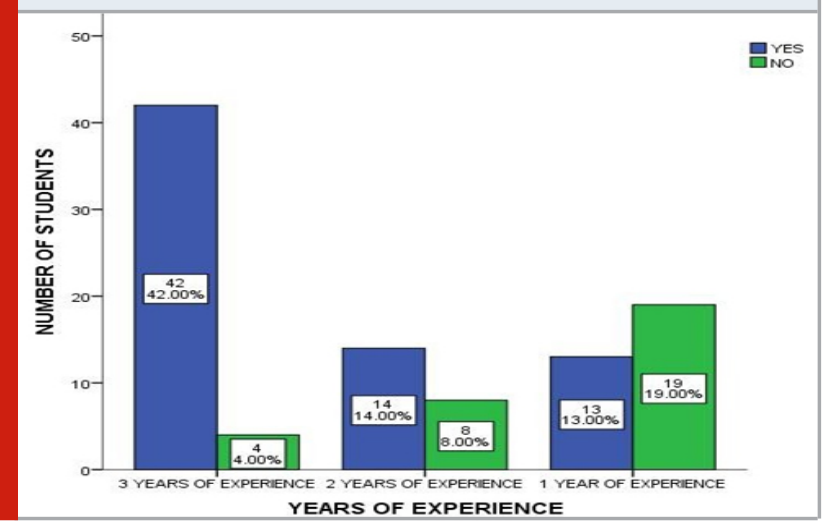

Figure 8: Bar chart depicts the association between the most commonly used shades with respect to various years of experience. $\mathrm{X}$-axis denotes the years of experience. Y-axis denotes the number of students. Chi-square test was done and was found to be statistically significant (Pearson chi square, p value- $0.003 ;(<0.05)$. A2 shade was the most commonly used shade among students with two years and three years of experience but according to students with one year of experience A1 shade was the commonly used shade.

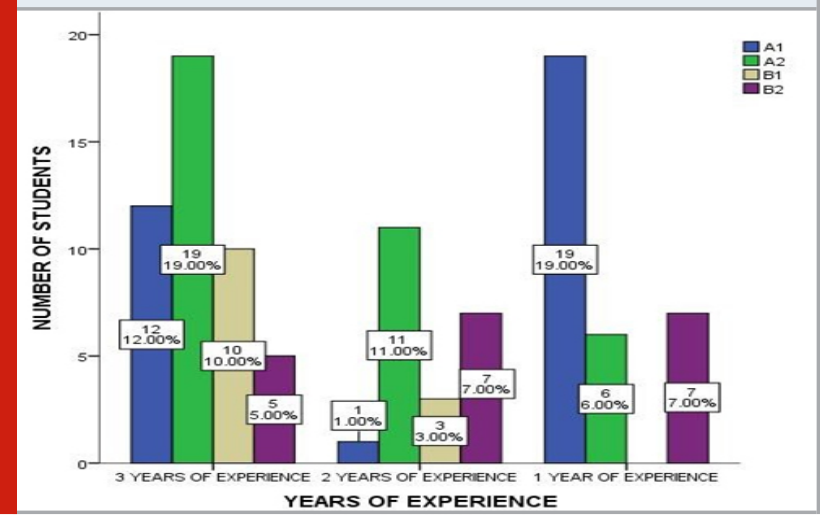

In our study, Figure 8 showed that A2 shade was the most commonly used shade among students with two years and three years of experience but according to students with one year of experience A1 shade was the commonly used shade. Even in the study by Sambandham.et.al, 
A2 shade was considered as the most commonly used shade(Sambandam and Ramesh, 2017). But in the study by Alruwaili.et.al, B1 shade was commonly used in practice(Alruwaili et al., 2018). The variation in the results may be to different geographical areas and a completely different population.

Figure 9: Bar chart depicts the association between awareness about shade guides with respect to various years of experience. $\mathrm{X}$-axis denotes the years of experience. Y-axis denotes the number of students. Chi-square test was done and was found to be statistically significant (Pearson chi square, $p$ value- $0.02 ;(<0.05)$. Majority of the students were aware about the shade guides.

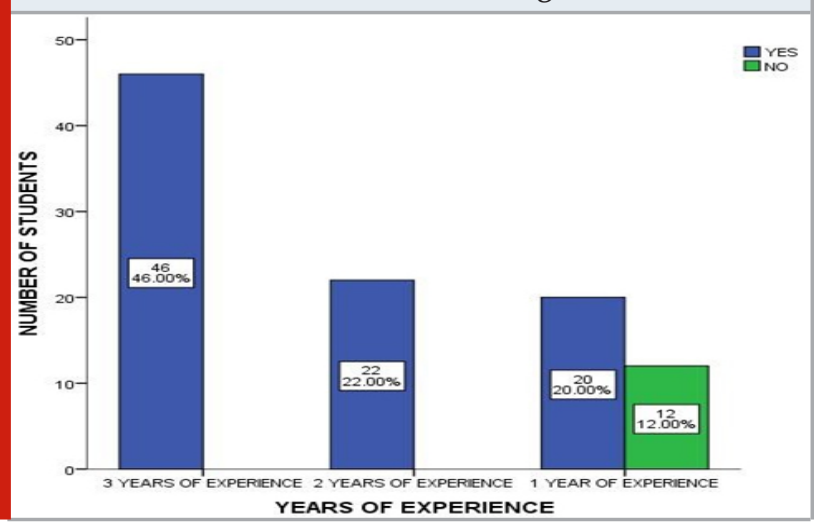

Figure 10: Bar chart depicts the association between awareness about recent advancements in shade matching with respect to various years of experience. $\mathrm{X}$-axis denotes the years of experience. $\mathrm{Y}$-axis denotes the number of students. Chi-square test was done and was found to be statistically not significant (Pearson chi square, $p$ value$0.07 ;(>0.05)$. Students with three years of experience were slightly more aware about the recent advancements than the students with one year and two years of experience.

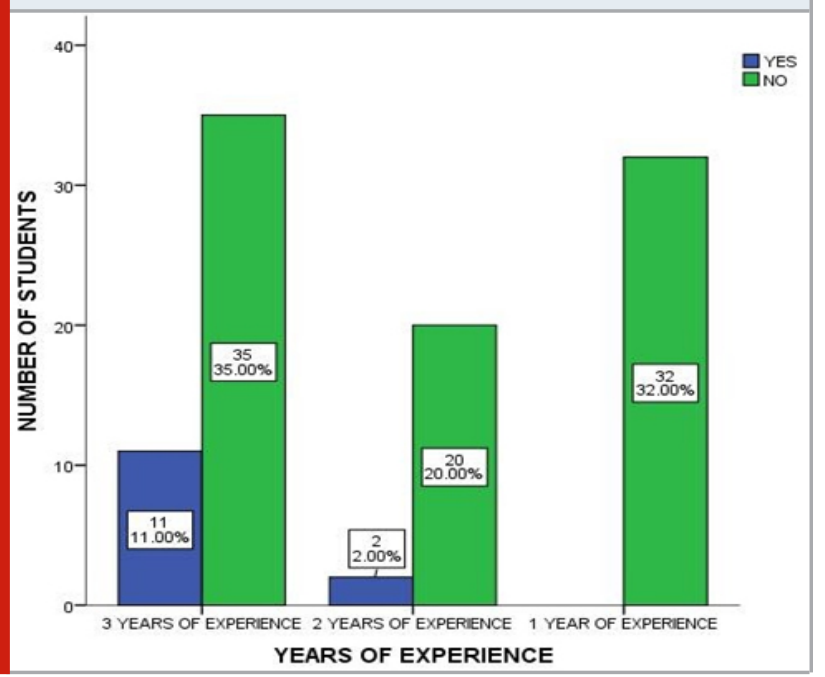

In our study, Figure 9 and Figure 10 showed that the majority of the participants (88\%) were aware about the shade guides that were used during shade matching but only $13 \%$ of them were aware about the recent advancements in shade matching techniques. In the study by Alruwaili.et.al, it was reported that $69.24 \%$ of the participants used the standard shade guide while the remaining participants used the shade guide provided by the company that manufactured those composite materials(Alruwaili et al., 2018). Shade guides have said to have some disadvantages. To avoid all those mistakes, a new shade guide Vita 3D Master has been developed using Munsell's terminology. It utilizes the colour perception concept with five levels of values and three levels of chroma and hue and has been proved to be more accurate than the other theories(Hammad, 2003; Yuan et al., 2007; Nakhaei et al., 2016). The finding from the present study adds to the consensus of the previous studies. Limitations of the study were smaller sample size so it cannot be generalised to the whole population. Further studies can be done with a larger population.

\section{CONCLUSION}

From the present study, we can conclude that the dental students had comparatively better understanding and knowledge about the principles of tooth shade selection. Majority of them did not face any difficulties during shade matching and they always preferred to do shade selection for different regions of the tooth surface separately and to get a second opinion for a better outcome. They had better knowledge about the effectiveness and reliability of natural light during shade matching. But the knowledge about recent advances in shade matching was very less so better training and work experience can help them to understand about the advancements and the significance of shade matching.

Author Contributions: All the authors have equal contributions in bringing out this research work.

\section{ACKNOWLEDGEMENTS}

The authors are thankful to Saveetha Dental College for providing permission to access the database and for giving a platform to express our knowledge.

Conflicts of Interest: The authors declare no conflicts of interest.

\section{REFERENCES}

Alruwaili, M. N. et al. (2018) 'Knowledge, attitude and practice of dental students, practitioners and specialist on composite shade matching in Al-jouf, KSA', Egyptian Journal of Hospital Medicine. Ain Shams University, Faculty of Medicine, Pan Arab League of Continuous ..., 72(2), pp. 4017-4020.

Awinashe, V. N. and Dugad, J. A. (2010) 'Effect of light intensity on the shade selection in ceramic restorations-A survey', International Journal of Dental Clinics. intjdc.com. Available at: http://intjdc.com/ index.php/intjdc/article/view/112.

Azeem, R. A. and Sureshbabu, N. M. (2018) 'Clinical performance of direct versus indirect composite restorations in posterior teeth: A systematic review', 
Journal of conservative dentistry: JCD, 21(1), pp. 2-9. Azer, S. S. et al. (2011) 'Effect of substrate shades on the color of ceramic laminate veneers', The Journal of prosthetic dentistry, 106(3), pp. 179-183.

Barna, G. J. et al. (1981) 'The influence of selected light intensities on color perception within the color range of natural teeth', The Journal of prosthetic dentistry, 46(4), pp. 450-453.

Barrett, A. A. et al. (2002) 'Influence of tab and disk design on shade matching of dental porcelain', The Journal of prosthetic dentistry, 88(6), pp. 591-597. Brewer, J. D., Wee, A. and Seghi, R. (2004) 'Advances in color matching', Dental clinics of North America, 48(2), pp. v, 341-58.

Carsten, D. L. (2003) 'Successful shade matching--what does it take?', Compendium of continuing education in dentistry , 24(3), pp. 175-178.

Clary, J. A. et al. (2016) 'Influence of light source, polarization, education, and training on shade matching quality', The Journal of Prosthetic Dentistry, pp. 91-97. doi: 10.1016/j.prosdent.2015.12.008.

Dagg, H. et al. (2004) 'The influence of some different factors on the accuracy of shade selection', Journal of oral rehabilitation, 31(9), pp. 900-904.

Gasparik, C. et al. (2014) 'Influence of light source and clinical experience on shade matching', Clujul Medical. Universty of Medicine and Pharmacy of Cluj-Napoca, Romania, 87(1), p. 30.

Govindaraju, L., Neelakantan, P. and Gutmann, J. L. (2017) 'Effect of root canal irrigating solutions on the compressive strength of tricalcium silicate cements', Clinical oral investigations, 21(2), pp. 567-571.

Habib, S. R. (2012) 'Awareness of tooth shade selection principles among Dental students, Interns, General dentists and Specialists, Pakistan Oral \&t Dental Journal, 32(3).

Hall, N. R. (1991) 'Tooth colour selection: the application of colour science to dental colour matching, Australian prosthodontic journal / Australian Prosthodontic Society, 5, pp. 41-46.

Hammad, I. A. (2003) 'Intrarater repeatability of shade selections with two shade guides', The Journal of prosthetic dentistry, 89(1), pp. 50-53.

Iqbal, J., Shahid, S. and Mm, M. (2017) 'Comparison of Skills and Knowledge Related to Prosthetic Tooth Shade Selection among Dental Practitioners in Third world Country', Oral Heal Dent, 1(5), pp. 230-236. Janani, K. and Sandhya, R. (2019) 'A survey on skills for cone beam computed tomography interpretation among endodontists for endodontic treatment procedure', Indian journal of dental research: official publication of Indian Society for Dental Research, 30(6), pp. 834-838.

Jenarthanan, S. and Subbarao, C. (2018) 'Comparative evaluation of the efficacy of diclofenac sodium administered using different delivery routes in the management of endodontic pain: A randomized controlled clinical trial', Journal of conservative dentistry: JCD, 21(3), pp. 297-301.

Joiner, A. (2004) 'Tooth colour: a review of the literature', Journal of dentistry, 32, pp. 3-12.

Judeh, A. and Al-Wahadni, A. (2009) 'A comparison between conventional visual and spectrophotometric methods for shade selection', Quintessence international , 40(9), pp. e69-79.

Khandelwal, A. and Palanivelu, A. (2019) 'Correlation Between Dental Caries And Salivary Albumin In Adult Population In Chennai: An In Vivo Study', Brazilian Dental Science, 22(2), pp. 228-233.

Klemetti, E. et al. (2006) 'Shade selection performed by novice dental professionals and colorimeter', Journal of oral rehabilitation, 33(1), pp. 31-35.

Magne, P. and Holz, J. (1996) 'Stratification of composite restorations: systematic and durable replication of natural aesthetics', Practical periodontics and aesthetic dentistry: PPAD, 8(1), pp. 61-68.

Malli Sureshbabu, N. et al. (2019) 'Concentrated Growth Factors as an Ingenious Biomaterial in Regeneration of Bony Defects after Periapical Surgery: A Report of Two Cases', Case reports in dentistry, 2019, p. 7046203.

Manohar, M. P. and Sharma, S. (2018) 'A survey of the knowledge, attitude, and awareness about the principal choice of intracanal medicaments among the general dental practitioners and nonendodontic specialists', Indian journal of dental research: official publication of Indian Society for Dental Research, 29(6), pp. 716-720.

Nakhaei, M. et al. (2016) 'The influence of dental shade guides and experience on the accuracy of shade matching', The journal of contemporary dental practice, 17(1), pp. 22-26.

Nandakumar, M. and Nasim, I. (2018) 'Comparative evaluation of grape seed and cranberry extracts in preventing enamel erosion: An optical emission spectrometric analysis', Journal of conservative dentistry: JCD, 21(5), pp. 516-520.

O'Brien, W. J. et al. (1997) 'Color distribution of three regions of extracted human teeth', Dental materials: official publication of the Academy of Dental Materials, 13(3), pp. 179-185.

Okubo, S. R. et al. (1998) 'Evaluation of visual and instrument shade matching', The Journal of prosthetic dentistry, 80(6), pp. 642-648.

Passon, C. and Lambert, R. (1994) 'Tooth-shade shift after rubber-dam isolation', General dentistry, 42(2), pp. 148-52; quiz 153-4.

Poorni, S., Srinivasan, M. R. and Nivedhitha, M. S. (2019) 'Probiotic strains in caries prevention: A systematic review', Journal of conservative dentistry: JCD, 22(2), pp. 123-128.

Rajakeerthi, R. and Ms, N. (2019) 'Natural Product as the Storage medium for an avulsed tooth - A Systematic Review', Cumhuriyet Dental Journal, 22(2), pp. 249256. 
Rajendran, R. et al. (2019) 'Comparative Evaluation of Remineralizing Potential of a Paste Containing Bioactive Glass and a Topical Cream Containing Casein Phosphopeptide-Amorphous Calcium Phosphate: An in Vitro Study', Pesquisa brasileira em odontopediatria e clinica integrada, 19(1), pp. 1-10.

Ramarao, S. and Sathyanarayanan, U. (2019) 'CRA Grid - A preliminary development and calibration of a paper-based objectivization of caries risk assessment in undergraduate dental education', Journal of conservative dentistry: JCD, 22(2), pp. 185-190.

Sachan, S., Srivastava, I. and Ranjan, M. (2016) 'Flowable composite resin: a versatile material', Journal of medical and dental sciences, 15(6), pp. 71-74.

Sambandam, T. V. and Ramesh, S. (2017) 'Knowledge, attitude, and practice of dental students and practitioners on shade matching of anterior teeth', Journal of Advanced Pharmacy Education \& Research| Jul-Sep, 7(3). Available at: https://www.speronline.com/japer/ Articlefile/51_JAPER_89_2017_Survey_Query.pdf.

Schwabacher, W. B., Goodkind, R. J. and Lua, M. J. (1994) 'Interdependence of the hue, value, and chroma in the middle site of anterior human teeth', Journal of prosthodontics: official journal of the American College of Prosthodontists, 3(4), pp. 188-192.

Siddique, R. et al. (2019) 'Qualitative and quantitative analysis of precipitate formation following interaction of chlorhexidine with sodium hypochlorite, neem, and tulsi', Journal of conservative dentistry: JCD, 22(1), pp. 40-47.

Siddique, R. and Nivedhitha, M. S. (2019) 'Effectiveness of rotary and reciprocating systems on microbial reduction: A systematic review', Journal of conservative dentistry: JCD, 22(2), pp. 114-122.

Siddique, R., Nivedhitha, M. S. and Jacob, B. (2019) 'Quantitative analysis for detection of toxic elements in various irrigants, their combination (precipitate), and para-chloroaniline: An inductively coupled plasma mass spectrometry study', Journal of conservative dentistry: JCD, 22(4), pp. 344-350.

Small, B. W. (2006) 'Shade selection for restorative dentistry', General dentistry, 54(3), pp. 166-167.

S, P. et al. (2014) 'A Review on Marginal Deterioration of Composite Restoration', IOSR Journal of Dental and Medical Sciences, pp. 06-09. doi: 10.9790/085313140609.

Teja, K. V., Ramesh, S. and Priya, V. (2018) 'Regulation of matrix metalloproteinase-3 gene expression in inflammation: A molecular study', Journal of conservative dentistry: JCD, 21(6), pp. 592-596.

Terry, D. A. (2003) 'Dimensions of color: creating highdiffusion layers with composite resin', Compendium of continuing education in dentistry , 24(2 Suppl), pp. 3-13.

Vanini, L. (1996) 'Light and color in anterior composite restorations', Practical periodontics and aesthetic dentistry: PPAD, 8(7), p. 673.

Vichi, A., Ferrari, M. and Davidson, C. L. (2000) 'Influence of ceramic and cement thickness on the masking of various types of opaque posts', The Journal of prosthetic dentistry, 83(4), pp. 412-417.

Wagenaar, R. and Smit, R. (2004) 'Shade taking: factoring out human error', Das Dental-Labor. Le Laboratoire dentaire. The Dental laboratory, 29, pp. 26-29.

Wee, A. G. (2006) 'Description of color, color replication process and esthetics', Contemporary fixed prosthodontics. Elsevier Health Sciences, St. Louis, 4, p. 712.

Yuan, J. C.-C. et al. (2007) 'Defining a natural tooth color space based on a 3-dimensional shade system', The Journal of prosthetic dentistry, 98(2), pp. 110-119. 